\title{
Çocuklarda omurga kırıkları ve tedavisi
}

\author{
Pediatric spinal fractures and treatment
}

\author{
Yunus Emre Akman
}

T.C. Demiroğlu Bilim Üniversitesi Tıp Fakültesi, Şişli Florence Nightingale Hastanesi, Ortopedi ve Travmatoloji Kliniği, İstanbul

Omurga yaralanmaları çocuk hastalarda önemli bir morbidite ve mortalite nedenidir ve tüm çocukluk çağı iskelet sistemi yaralanmalarının yaklaşık \%2-5'ini oluşturur. Büyümekte ve gelişmekte olan çocuk omurgasının bazı benzersiz özellikleri, bu hastaları yetişkin hastalardan ayırmakta ve bu nedenle bu popülasyona özel bir dikkat gösterilmesi gerekmektedir. Bu yaralanmalar sıklıkla yüksek enerjili travma ile oluşmakta ve koordine multidisipliner bir yaklaşım gerektiren eş zamanlı torasik veya abdominal yaralanmalarla ilişkilidir. Çocuk hastalarda omurga travması; kompresyon kırıklarına, patlama kırıklarına, fleksiyon-distraksiyon yaralanmalarına (Chance kırı̆̆ı), kırıklı çıkıklara, apofiz kırıkları/herniyasyonları ve spinöz/transvers çıkıntı kırıklarına yol açabilir. Yaralanmanın mekanizmasına ve hastanın iskelet olgunluğunun seviyesine bağlı olarak, spinal kord yaralanmaları iyileşme ve remodelasyon açısından önemli potansiyele sahip olabilir. Omurga yaralanmaları çocuk hastalar üzerindeki ciddi sonuçlara ve önemli komplikasyonlara neden olabileceğinden, erken tanı ve tedavi ile uzun süreli takip yapılması önemlidir.

Anahtar sözcükler: çocuk; omurga kırıkları; servikal; dorsolomber; spinal kord yaralanması
Spine trauma is an important cause of morbidity and mortality in pediatric patients and constitute almost $2-5 \%$ of pediatric musculoskeletal injuriers. Special attention is mandatory in this population as there are several unique features of the growing pediatric spine which distinguish these patients from adult patients. These injuries are generally due to high-energy trauma, and related to concurrent thoracic or abdominal injuries that require coordinated multidisciplinary care. Pediatric spine trauma may lead to compression fractures, burst fractures, flexion-distraction injuries such as Chance fracture, fracture-dislocation injuries, apophyseal fractures/herniations, and spinous and transverse process fractures. Depending on the mechanism of the injury and the patient's level of skeletal maturity, spinal injuries may have considerable potential for healing and remodelization. Because the impact of pediatric spinal injury pediatric may lead to serious consequences and severe complications, appropriate early diagnosis and management, as well as long-term follow-up, are essential.

Key words: pediatric; spinal fracture; cervical; thoracolumbar; spinal cord injury

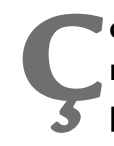
ocuklarda torakolomber omurga yaralanmaları nadirdir, bununla birlikte tanı ve tedavi ile ilgili pek çok özel husus vardır. Pediatrik hastalarda omurga kırıkları, minör kompresyon kırıklarından, spinal kord yaralanması ile seyreden nadir kırıklı çıkıklara kadar değişiklik gösterebilir. Pediatrik yaş grubunda uygun tedavi; çocukluktaki omurilik anatomisi, biyomekanik, iyileşme ve büyüme potansiyeli ve biyopsikososyal faktörlerin kesin olarak anlaşılmasına dayanmalıdır. Çocuklarda omurga kırıklarının dikkatli takibi, omurganın mevcut büyüme potansiyeli ve daha sonra oluşabilecek deformite, instabilite ve nörolojik hasar riski nedeniyle önemlidir.

\section{EPIDEMIYOLOJi}

Çocuklarda omurga yaralanmaları erişkinlerden daha az yaygındır ve tüm omurga travmalarının $\% 2$ ila \%5'ini oluşturur. ${ }^{[1-3]}$ Tüm çocuk kırıklarının \%5'i omurgada meydana gelir; torakolomber omurga kırkları tüm çocuk kırıklarının \%1 ila \%2'sini oluşturur. ${ }^{[1,2,4]}$ Çocuklarda omurga travmasının en yaygın nedeni, tüm yaralanmaların \%33 ila \%58'ine neden olan motorlu araç kazalarıdır ${ }^{[2,5,6]}$; diğer sık görülen mekanizmalar arasında, yüksekten düşme, spor yaralanmaları ve çocuk istismarı sayılabilir. ${ }^{[2,6,7]}$ Sekiz yaşından küçük çocuklarda torakolomber omurga yaralanmaları daha

- İletişim adresi: Dr. Yunus Emre Akman, Merkez Mahallesi, Abide-i Hürriyet Cad. No:164, 34387 Şişli, İstanbul Tel: 0532 - 5050767 e-posta: yemreakman@gmail.com

- Geliş tarihi: 2 Şubat $2019 \quad$ Kabul tarihi: 2 Şubat 2019 
az olasıdır. ${ }^{[3]} \mathrm{Bu}$ yaş grubunda, baş/beden oranındaki farklılığın yol açtığı biyomekanikler, servikal omurga yaralanmaları insidansında artışa neden olur. Ek olarak, torakolomber travmaya yol açan yaygın yaralanma mekanizmaları, yüksek riskli aktivitelere katılımları nedeniyle daha büyük çocukları etkiler.

\section{ÇOCUKLARDA OMURGA ANATOMISi}

Omurga anatomisi, çocuklarda erişkinlerdekinden farklıdır ve yaralanma paterni, uygun tedavinin seçimi ve sonuçları üzerinde önemli bir etkiye sahiptir. Yetişkinlerle karşılaştırıldığında, çocuk omurgası daha fazla esnektir. Faset eklemler daha sığ ve horizontaldir. Paraspinal kaslar henüz yeterli olgunluğa erişmemiştir. ${ }^{[5]}$ Ayrıca, çocuklarda nükleus pulposus daha fazla su içeriğine ve yetişkinlerde olduğundan, daha fazla kollajen çapraz bağlanmasına, daha fazla elastikiyete ve daha fazla yük dağıtma kabiliyetine sahiptir. Ancak, sekiz yaşından büyük hastalar daha küçük olanlarla karşılaştırıldığında, tipik olarak yetişkinlere benzer kırılma paternlerine sahiptirler. ${ }^{[5]}$

Omurilik yenidoğanda L3'te sona ermektedir ve çocukluk çağında ergenlik dönemi boyunca $L 1$ veya $L 2$ 'de sona ermek üzere sefalad yöne (başa doğru) ilerler. Nöral elemanlara omurilik düzeyinde hasar gelmesi kısmi veya tam kord hasarına yol açabilirken, omuriliğin terminal ucundan kaudaldeki yaralanmalar, konus medullaris veya kauda ekina sendromuna yol açabilir.

Pediatrik omurga yaralanmasının değerlendirilmesinde, yaralanma mekanizması ve yaralanmaya neden olan kuvvetlerin anlaşılması önemlidir. Distraksiyon yaralanmalarında, deforme edici gergi kuvveti, olgunlaşmakta olan vertebral cismin görece zayıf fiziyel kıkırdağından geçer ve genellikle konservatif tedaviyle iyi bir şekilde iyileşen Salter-Harris Tip I kırığı ile sonuçlanır. ${ }^{[5]}$ Erişkinlerde olduğu gibi, kaburgalar torasik omurgada stabiliteye katkıda bulunarak belirgin dislokasyonların önlenmesine yardımcı olur. ${ }^{[1]}$ Bununla birlikte, yaşı daha küçük olan hastalar daha zayıf kaslara, daha zayıf kemikli yapılara ve daha az gelişmiş iliak kanatlara sahip olduklarından, büyük çocuklarla karşılaştırıldığında intra-abdominal ve intra-torasik organ yaralanmalarına karşı daha yüksek riske sahiptirler. ${ }^{[1]}$

Kompresyon yaralanmalarında, çocuklarda görülen çok seviyeli yaralanmalara yatkınlık, artmış esneklik ve yüzeyi küçük omurga cisimlerinin yüksek kuvvetlerin iletimi için küçük yüzey alanlarına sahip olmasından kaynaklanabilir. ${ }^{[5]}$ Ayrıca, olgunlaşmamış omurga gövdeleri kama şeklinde olup, omurgada doğal bir kifoz artışına neden olur ve bu durum kompresyon kırılmalarına yatkınlığa neden olur. ${ }^{[8]}$

\section{ILK DEĞERLENDIRME VE TEŞHis}

Travma geçiren çocuklar, çocuklar için önerilen ileri Travma Yaşam Desteği (ATLS) protokolüne göre değerlendirilmeli ve tedavi edilmelidir. Spinal instabilite ihtimali nedeniyle, travma geçirmiş tüm çocuklarda spinal immobilizasyon sağlanmalı ve sert bir boyunluk uygulanmalıdır. Pediatrik bir omurga sedyesi veya çocuğun gövde kısmını başa göre yükseltmek için bir yükselti içeren bir yetişkin transfer sedyesi kullanılarak boyun hiperfleksiyondan korunmalıdır, bu şekilde nörolojik yaralanma ve hava yolunun kapanması önlenebilir. ${ }^{[9]}$

Çocuğun yaşı ve mental durumuna bağlı olarak, kapsamlı bir nörolojik muayene yapmak zor olabilir. Değerlendirme sırasıyla, miyotom ve dermatomlar boyunca motor ve duysal muayeneyi içermelidir. Rektal ve genital muayene yanı sıra bulbokavernöz refleks dahil refleks testi, uygun şartlar sağlandığında yapılmalıdır. Muayene sonucunda spinal kord yaralanması görülürse, bu yaralanmanın kısmi ya da tam olduğu tespit edilir. Tam yaralanmada, spinal kord yaralanması seviyesinin altında motor ve duyu işlevi tamamen kaybolmuştur. Ancak, yaralanmanın tam olduğu kanaatine varmak için spinal şok evresinin geçmiş olması gereklidir. Genellikle 24 saat geçtikten sonra spinal şok dönemi biter. Bulbokavernöz refleksin geri dönmüş olması S3-4 köklerinin çalıştığını gösterir. Bulbokavernöz refleks geri döndükten sonra yapılan muayenede; anal bölge duyusunun korunması, rektal sfinkter motor işlevin olması ve bunun gibi bulgular, kısmi yaralanma olduğuna işaret eder.

Tüm omurga ve paraspinöz bölgenin palpasyonu yapılmalı, krepitus, morarma veya açık yaralanmaların varlığı değerlendirilmelidir. Fizik muayene, omurga kırıklarının saptanması için tek başına \%87'ye kadar du-

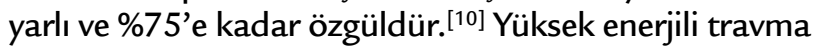
sonucu omurga yaralanmalı çocuk hastalar, intraabdominal ve intratorasik patolojiye sahip olabilirler. Ortak ilişkili yaralanmalar arasında; ince barsak yaralanmaları, pankreatik yırtık, hemotoraks veya pnömotoraks, akciğer kontüzyonu ve aort yaralanması yer alır. Eşlik eden abdominal veya torasik yaralanmaların insidansı \%42'ye varabilir ${ }^{[11]}$ ve bu, özellikle emniyet kemerinin karın ve göğüs hizasından temas ettiği motorlu taşıt kazası geçirmiş olan hastalarda, karın fleksiyonuna ve iç organların kompresyonuna bağlı olarak oluşabilir. ${ }^{12]}$

Ek olarak, omurga travmalı çocuklarda \%30'dan yüksek oranda kafa travması da görülebilir. ${ }^{[11]} \mathrm{Bu}$ nedenle, muayenede baş, göğüs ve abdomenin tam olarak fiziksel olarak değerlendirilmesini içeren düzenli bir yaklaşım takip edilmelidir. Sistemlerin ayrıntılı bir gözden geçirmesi de yapılmalı, olası künt baş, göğüs veya abdominal yaralanma bulgularına veya semptomlarına dikkat edilmelidir. 
Omurga yaralanması düşük enerjili travma ile oluşmuş ise patolojik kırık yönünde inceleme de yapılmalıdır. Çocukluk çağında sırt-bel ağrısı ile başvuran ve çoklu çökme kırıkları tespit edilen hastalarda patolojik kırık etiyolojisinde; metabolik depo hastalıkları, osteogenesis imperfekta, idiyopatik osteoporoz, nöroblastom metastazı, Ewing sarkomu ve lösemi mutlaka araştırılmalıdır. ${ }^{[6]}$

\section{RADYOLOJIK DEĞERLENDIRME}

Pediatrik travmada başlangıç başvurusunda omurga görüntülemesine rehberlik edecek kanıtlanmış, kanıt temelli hiçbir kılavuz bulunmamaktadır. Ancak, anteriorposterior (AP) ve lateral düz grafiler ve nörolojik defisiti olan çocuklarda manyetik rezonans (MR) görüntüleme sıklıkla tercih edilir. ${ }^{[10,13]}$ Bilgisayarlı tomografi (BT) kullanımı, erişkin hastalarda ve çoklu travma geçiren hastalarda tercih edilen görüntüleme modalitesi olarak yarar sağlamıştır. Özellikle; yüksek enerjili yaralanmalar, yüksek derecede omurga yaralanması, nörolojik defisit, baş veya yüz yaralanmaları, mental durumu değişen veya muayeneye uyumsuz olan erişkin hastalarda son derece yararlıdır. Yetişkinlerde BT'nin yaygın kullanımına rağmen, pediatrik hastalarda radyasyona aşııı maruz kalma riski göz önünde bulundurulmalıdır.

Omurga travması geçiren çocuklarda, tüm omurga mutlaka düz grafiler ile değerlendirilmelidir. Çünkü, çok seviyeli omurga kırıkları gelişme ihtimali \%11 ile \%34 arasında, bitişik olmayan çok düzeyli kırıkların olma ihtimali ise \%6 ile \%7 arasında bildirilmiştir. ${ }^{[5,8,14]}$ BT, çocuklarda iyonize radyasyon ile ilişkili risklerden dolayı, omurganın rutin taraması için kullanılmamalıdır. Pediatrik BT'nin, yaralanmanın tabiatını değerlendirmek için, yaralanmanın olduğu teşhis edilmiş belli bölgelere yönelik kullanım gereksinimi daha fazladır. MR, omurganın değerlendirmesi için iyonize radyasyona maruziyet olmadığı için ve disk herniyasyonları ve nörolojik yapılara verilen hasarlar dahil olmak üzere yumuşak dokuların hassas bir şekilde değerlendirilebilme olanağı sağladığından, giderek artan popülerlikle kullanılmaktadır. ${ }^{[13]}$ Nörolojik defisitli omurga yaralanması olan bir çocuk, mutlaka acil olarak MR ile değerlendirilmelidir. ${ }^{[15]}$ Ancak, omurganın görüntülenmesi için MR her zaman yeterli değildir, çünkü BT ile karşılaştırıldığında, MR kemik anatomisini değerlendirmek için yeterince yararlı olmayabilir.

\section{TEDAVi}

\section{Servikal Yaralanmalar}

Anatomik ve biyomekanik farklılıklar nedeniyle üst ve alt servikal bölge yaralanma mekanizması ve tipleri farklılıklar gösterdiğinden; oksipital kondil kırıkları, C1 kırıkları, C2 kırık/kırıklı çıkıkları, atlanto-aksiyel rotator subluksasyon ayrı ayrı ele alınmalıdır.

\section{Oksipital kondil kırıkları}

Çocuklarda oksipital kondil kırıkları nadir görülür. Kafa yaralanması geçiren, bilinç durumu değişken olan, alt kraniyal sinir lezyonu olan ve persistan boyun ağrısı olan çocuk hastalarda özellikle şüphelenilmelidir. Yaralanmanın varlığı ve şiddeti en iyi BT ile değerlendirilir. Oksipital kondil kırıkları Anderson tarafından sınıflanmış olup üç tipe ayrılmıştır. ${ }^{[16]}$ Tip 1 impaksiyon kırığı, Tip 2 kondil(ler)e uzanan basiler kafatabanı kırı̆̆ı, Tip 3 ise alar bağ avulsiyon kırığı olarak tanımlanmıştır. Tedavisinde halo immobilizasyon veya oksipito-servikal artrodez uygulanmaktadır. Tip 3 yaralanmalar genellikle instabil olup cerrahi girişim gerektirir. ${ }^{[16]}$

\section{Atlanto-oksipital dislokasyon}

Yüksek enerjili travma sonucunda özellikle kafa ve yüz yaralanması bulunan çocuklarda, seyrek görülen, ancak çoğunlukla ölümcül seyreden bir yaralanmadır. Atlanto-oksipital eklemin primer stabilizatörleri; alar bağlar, tektoryal membran, ön longitudinal bağ ve nukal bağdır. Çocuklarda düz oksipital kondiller ve sığ C1 üst artiküler faset yüzeyi nedeniyle atlanto-aksiyel eklemde translasyon tipi yaralanma daha olasıdır. [17] Bu yaralanma tipinin bir sınıflaması bulunmamaktadır. Klinik olarak; çocuklarda değişken duyusal ve motor lezyonlar, kraniyal sinir lezyonları, baş ağrısı, kusma, vertebral arter yaralanması nedeniyle solunum sıkıntısı ve beyin sapı fonksiyon bozukluğu görülebilir. Tektoriyel membran ve alar bağ yaralanması en iyi MR ile görüntülenir. Traksiyon kesinlikle kontrendikedir ve konservatif tedavi genellikle başarısızdır. Bu nedenle, C1-C2 segmenti sağlam ise oksiput-C1 arası füzyon yapılabilir. Ancak, $\mathrm{C} 1$ 'in ince ark yapısı nedeniyle yeterli füzyon ve stabilite elde etmenin zorluğundan dolayı oksiput-C2 füzyonu tercih edilir.

\section{Atlas (C1) kırı̆̆ı}

Atlas kırıkları çocuklarda nadir görülmekte olup, kırıklar genellikle sinkondroz bölgesinden gerçekleşir. Atlas üç kemikleşme merkezinden oluşur. Posterior sinkondroz üç yaş civarında, nörosantral sinkondroz ise yedi yaş civarında kapanır (fusion). Atlas kırıkları en iyi BT ile teşhis edilebilir. Çocuklarda Atlas kırıkları için tanımlanmış bir sınıflama bulunmamakla birlikte, erişkinde Atlas kırıkları üç tipe ayrılmıştır. ${ }^{[18]}$ Tip 1 ön veya arka ark kırığı, Tip 2 Jefferson patlama kırığı, Tip 3 ise tek taraflı lateral kitle kırı̆ı olarak tanımlanmıştır. Ancak, çocuk Atlas kırıklarında bu sınıflamanın 
uygulanabilirliği belirsizdir. Çocuklarda Atlas kırıklarının tedavisinde, lateral kitleleri genişletmek için önce halo traksiyon ve ardından halo immobilizasyon uygulanır.

\section{Atlanto-aksiyel rotator subluksasyon}

Atlanto-aksiyel rotator subluksasyon etiyolojisinde en sık travma ve enfeksiyon bulunur. Enfeksiyöz etiyoloji, çoğunlukla üst solunum yolu enfeksiyonu sonrasında gelişen Grisel sendromu olarak bilinir. Bazen tonsillektomi veya retrofalangeal abse sonrasında da gelişebilmektedir. ${ }^{[19]}$ Ağrı, kısıtlı hareket ve tortikollis ile kendini gösterir (Şekil 1a). Atlanto-aksiyel rotator subluksasyonunu Fielding ve ark. dört sınıfa ayırmışlardır. ${ }^{[20]}$ Tip 1 tek taraflı faset eklem çıkığını, Tip 2 tek taraflı faset eklem çıkığı ile birlikte alar bağ kopmasına bağlı 3-5 mm öne kaymayı, Tip 3 iki taraflı faset eklem çıkığını, Tip 4 ise Atlas'ın arkaya kaymasını içerir. Tip 3 ve Tip 4'te nörolojik yaralanma ve ölüm oranı yüksektir. Tanısı en iyi BT ile konulmaktadır (Şekil 1b). Tedavisinde, erken dönemde anti-inflamatuvar ilaç, kas gevşeticiler ve fizik tedavi sayllabilir. Dört haftadan uzun bir süre devam eden olgularda halo traksiyon uygulanabilir (Şekil 1c). Eğer redüksiyon sağlanabilirse halo immobilizasyon ile devam edilir. Redüksiyonun sağlanamadığı olgularda atlanto-aksiyel füzyon uygulanır.

\section{Odontoid kırı̆ı̆}

Çocuklarda sık görülmekte olup genellikle sinkondroz bölgesinde gerçekleşir. Odontoid tabanındaki sinkondroz 3-6 yaşları arasında (en sık dört yaş) kapanır. Çoğunlukla Salter-Harris Tip 1 epifizyoliz şeklinde kırık oluşur.

Erişkinde yaralanma mekanizması hiperekstansiyon yaralanması iken, çocuklarda mekanizma hiperfleksiyondur. Kalın anterior periosteal kılıf densin aşırı deplasmanını sınırlandırır. Çoğunlukla, kırık oluştuktan sonra başın normal pozisyona geri dönmesi ile odontoid kırı̆̆ı da redükte olur. Bu durumda, röntgende tanı konulması zorlaşmaktadır. Bu nedenle, klinik şüphe halinde MR'de epifiz çevresinde ödem görülmesi ile tanı konulabilir. Tedavisinde ise ekstansiyonda veya odontoidin redükte olduğu pozisyonda 6-8 hafta boyunca halo immobilizasyon uygulanır. ${ }^{[21]}$

\section{C2 kırıklı çıkı̆̆ı (Hangman kırığı)}

Genellikle iki yaş altı çocuklarda, hiperekstansiyon yaralanması sonucunda karşılaşılır. C2, C3'e göre sublukse olurve C2'nin pars bölgesinde lizis oluşur. Psödosubluksasyon, kapanmamış sinkondroz veya konjenital spondiloliz ile karışabilmektedir. Tedavisinde 8-12 hafta boyunca halo immobilizasyon uygulanır. Kaynamama veya instabilite durumunda cerrahi anterior C2-C3 artrodez uygulanır. ${ }^{[21]}$

\section{Alt servikal kırıklar}

Çocuklarda omurga cisim yaralanması, genellikle kıkırdak endplate bölgesinde gerçekleşir ve instabil kırıklardır. Nörolojik yaralanma ile sonuçlanabilir. Konservatif tedavide kapalı redüksiyon ve halo immobilizasyon uygulanır.

Kemik yapıyı içeren kırıklarda ise çocuklar erişkinler ile benzerlik gösterir. En sık kompresyon kırıkları görülür; bunu faset eklem çıkıkları izler. Kompresyon kırıkları genelde stabildir ve çocuklarda fizyolojik olarak görülen omurga cisim ön tarafindaki kamalaşma ile karıştırılabilir.

Kırık tespiti halinde halo immobilizasyon çoğunlukla yeterli olup instabilite, nörolojik defisit veya kanal darlığına yol açan kırık varlığında cerrahi tedavi olarak dekompresyon ve artrodez uygulanır (Şekil 2). Faset eklem çıkığı tek taraflı olduğunda kök lezyonu, çift taraflı olduğunda ise spinal kord basısı görülebilir. Genellikle traksiyon uygulaması ile kapalı redüksiyon elde edilirken, kapalı redüksiyonun başarısız olduğu olgularda açık redüksiyon uygulanmalıdır. ${ }^{[21]}$

\section{Dorsolomber Bölge Yaralanmaları}

Dorsolomber bölge yaralanmalarında, Denis tarafından 1926'da Böhler tarafından önerilen sınıflandırma geliştirilerek "3 Kolon Teorisi” ortaya konulmuştur. ${ }^{[22]}$ Buna göre; ardışık iki kolonun etkilenmesinin instabilite oluşmasına neden olduğu belirtilmekte, üç kolonun birden etkilenmesi ise kesin instabil olarak nitelenmektedir. Denis sınıflaması, klinik uygulamada halen Amerika Birleşik Devletleri'nde en sık kullanılan sınıflamadır. Denis sınıflaması dışında çok sayıda dorsolomber kırık sınıflaması tanımlanmıştır.

Son zamanlarda Torakolomber Yaralanma Sınıflaması ve Ciddiyeti Skalası (ThoracoLumbar Injury Classification and Severity score - TLICS) adında yeni bir sınıflama tanımlanmış olup, Savage ve ark. tarafından yapılmış bu sınıflamanın; çocuk hasta grubunda erişkin dorsolomber kırıklara nazaran, en çok fleksiyon-distraksiyon yaralanmasında olmak üzere uygulayıcılar arası tedavi seçimi güvenilirliğinin daha düşük olduğu, ancak buna rağmen TLICS sınıflamasının çocuk hastalarda güvenilirlik ve geçerliliğinin iyi derecede olduğu öne sürülmüştür. ${ }^{[23,24]}$ TLICS sınıflamasında yaralanma üç kritere göre değerlendirilmektedir: yaralanmanın morfolojisi, arka bağ yapının sağlamlı̆̆ ve hastanın nörolojik durumu. TLICS sınıflaması için, röntgen ve BT'nin yanında posterior ligamentöz kompleksin durumunun tespiti için MR incelemesi de gerekmektedir. Bu sınıflamaya göre, üç kategorinin toplam puanı dörtten fazla ise cerrahi, dörtten az ise konservatif tedavi önerilir. Toplam puan dört ise, her ikisi de uygulanabilir demektir. 

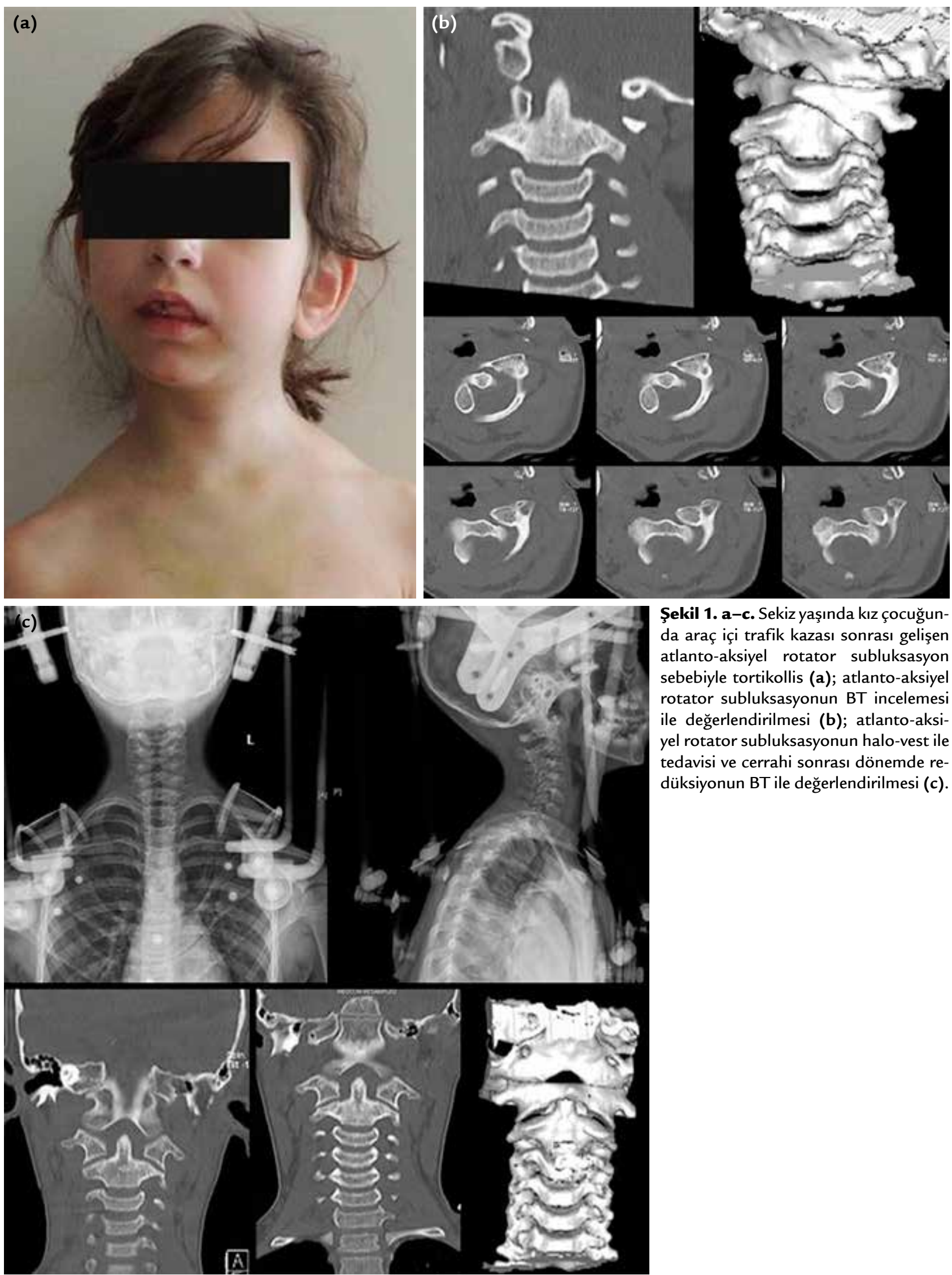

Şekil 1. a-c. Sekiz yaşında kız çocuğunda araç içi trafik kazası sonrası gelişen atlanto-aksiyel rotator subluksasyon sebebiyle tortikollis (a); atlanto-aksiyel rotator subluksasyonun BT incelemesi ile değerlendirilmesi (b); atlanto-aksiyel rotator subluksasyonun halo-vest ile tedavisi ve cerrahi sonrası dönemde redüksiyonun BT ile değerlendirilmesi (c). 

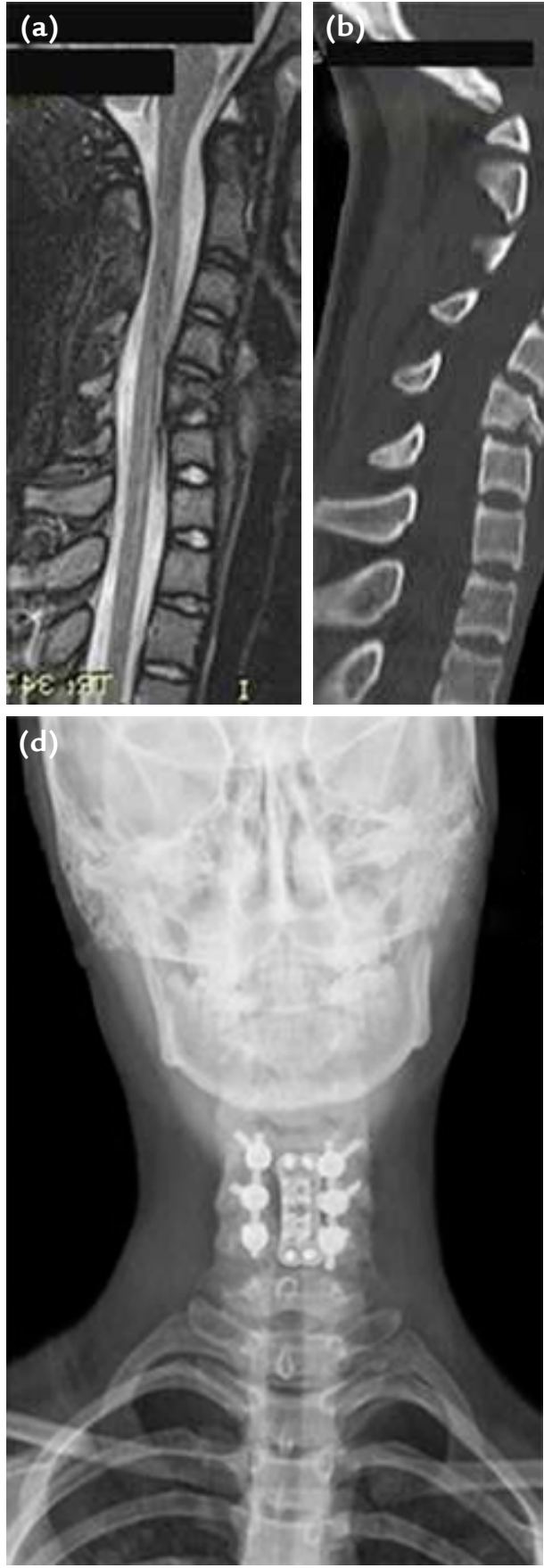

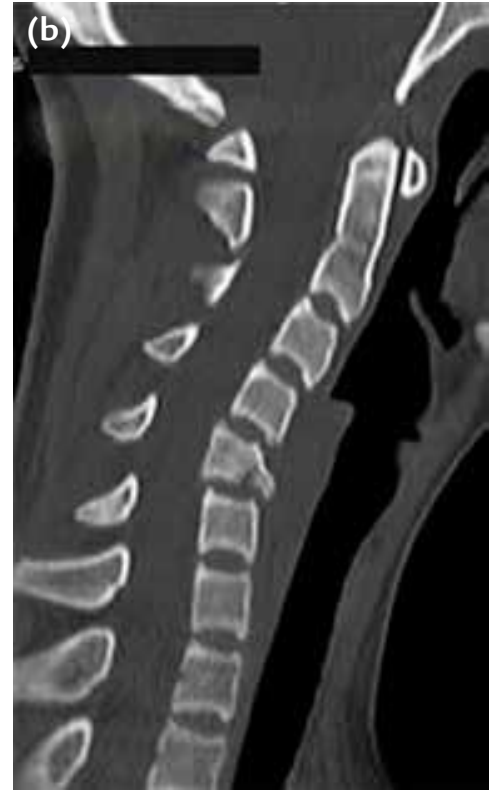

(e)

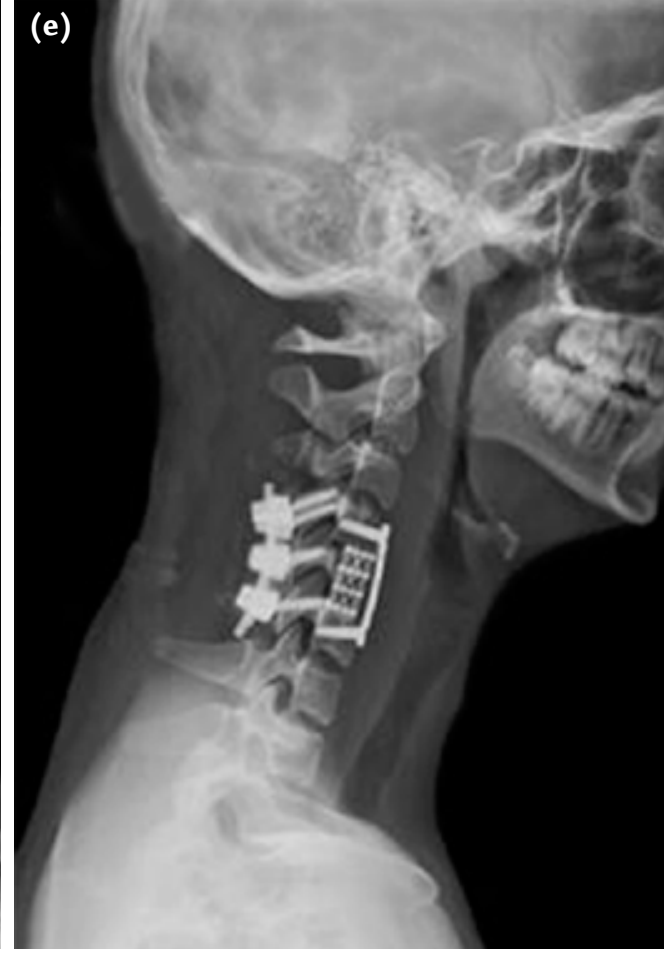

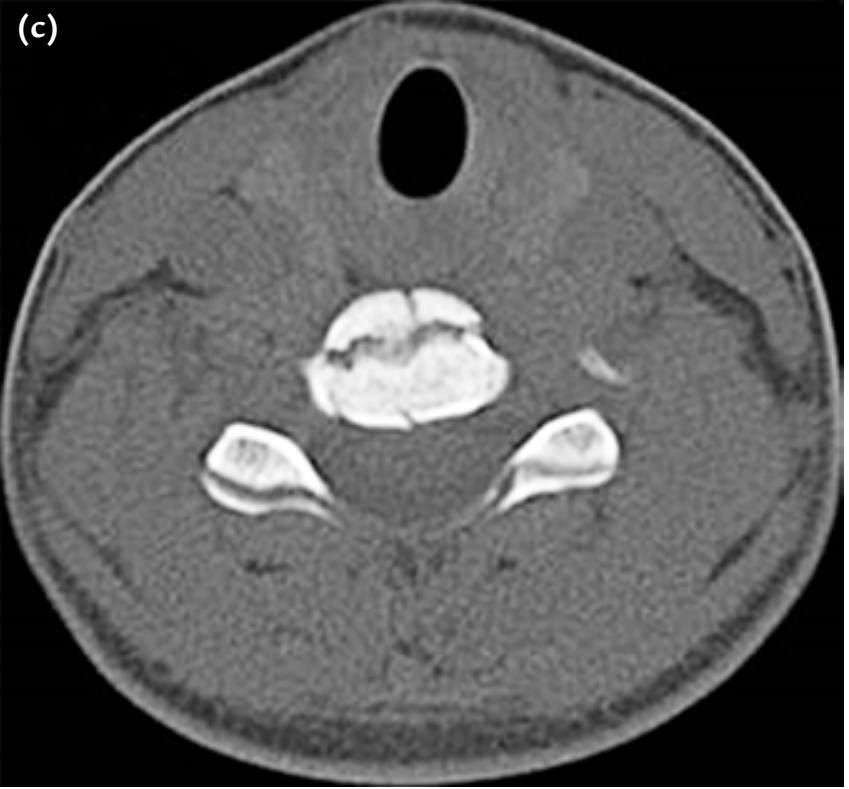

Şekil 2. a-e. On üç yaşında kız çocuğunda araç içi trafik kazası sebebiyle oluşan C5 vertebra kırığının MR (a) ve $\mathrm{BT}(\mathrm{b}, \mathrm{c})$ ile değerlendirilmesi. Olgunun anterior korpektomi-füzyon, plak-vida ile tespit ve posteriordan lateral kitle vidaları ile stabilizasyonu ve ameliyat sonrası AP ve lateral grafileri (d, e).

\section{Çökme kırıkları}

Çökme kırıkları, çocuk omurgasında en sık görülen kırık tipidir ve en sık dorsolomber bileşkede görülür. ${ }^{[5]}$ Genelde düşme ve spor yaralanmaları gibi düşük enerjili mekanizmalarla gerçekleşir. Aksiyel yüklenme ve omurganın fleksiyonu, omur cisminin anterior korteksinde çökmeye neden olur; bu genellikle \%20'den azdır. Genelde çoklu ardışık seviyelerde oluşur ve farkI seviyelerde de görülebilir. Yüzde 50'den fazla çökme olan hastalarda posterior ligamentöz kompleksin yaralanması göz önünde bulundurularak MR ile değerlendirilmelidir. Nörolojik defisit nadirdir. 
Omur cisminin çökmesi en sık sagittal planda gerçekleşir ve çoğunlukla cerrahi girişim gerektirmez. Çocukluk çağındaki çökme kırıklarında, yaş küçüldükçe omur cisminin anterior korteksindeki çökmenin remodelizasyon potansiyeli artmaktadır. Karlsson ve ark., yaptıkları çalışmada, ortalama 33 yıl (27-47 yıl) takip edilen hastalardan 13 yaş altı olanlarda, çökme kırıklarında remodelizasyon olduğunu göstermişlerdir. ${ }^{[25]}$ Koronal planda çökme ile gerçekleşen çökme kırıklarında ise remodelizasyon potansiyeli daha kısıtlıdır. Uç plak kırıklarında da benzer şekilde iyileşme olasılığı düşüktür.

Çökme kırıklarında genel olarak, omurgayı ekstansiyonda tutan korse (torakolumbosakral ortez) tedavisi yeterlidir. Dorsolomber geçiş bölgesinde olmayan tek seviye çökme kırığında ise hasta korsesiz takip edilebilir. Korseleme genelde 6-8 hafta devam ettirilir.

\section{Patlama kırıkları}

Patlama kırıkları, aksiyel yüklenme neticesinde nükleus pulpozusun omur cismi içine doğru basınç yaparak ön ve orta kolonları kırmasıyla gerçekleşir. Genelde dorsolomber bileşkede görülür. ${ }^{[2]}$ Omur cisim posterior duvarının kırılması ve medüller kanala deplase olması sonucunda; instabilite, nörolojik yaralanma ve dura yırtığı oluşabilir. Nörolojik yaralanma riski kanal işgalinden daha çok yaralanmanın seviyesine bağlıdır. Buna göre, dorsal kırıklarda nörolojik yaralanma riski daha yüksektir. ${ }^{[26]}$ Fokal kifoz varlığı, \%50'den fazla retropulsiyon, lamina kırığı, faset subluksasyonu ve/veya nörolojik defisit varlığında, patlama kırığının biyomekanik olarak instabil olduğu söylenebilir. BT ile omurilik basısı, posterior yapıların durumu ve retropulsiyon iyi bir şekilde değerlendirilebilir. MR ile, nöral ve ligamentöz yapıların durumu değerlendirilerek, posterior ligamentöz kompleksin sağlamlığı gözden geçirilerek kırığın stabilitesi değerlendirilebilir. MR ile posterior ligamentöz kompleksin sağlam olduğu tespit edilen patlama kırıklarında nörolojik yaralanma yok ise, hiperekstansiyon alçısı veya torako-lumbo-sakral-ortezler (TLSO) ile 8-12 hafta takip edilmesi yeterlidir. İnstabil patlama kırıklarında ise cerrahi tedavi planlanmalıdır.

İnstabil patlama kırıklarında çocuklarda füzyonlu veya füzyonsuz posterior enstrümantasyon, anterior cerrahi veya kombine cerrahi uygulanabilir. Füzyonsuz cerrahinin avantajı, kaynama gerçekleştikten sonra implantların çıkarılması ile omurga hareketinin korunması ve komşu seviye hastalığı gibi uzun dönem komplikasyonların görülmesinin önlenmesidir. Dekompresyon kararı, nöral yapıların basısı ve nörolojik defisit varlığında verilebilir.
Kaç seviye enstrümantasyon yapılması gerektiği konusunda ortak görüş birliği yoktur. Kırı̆̆ın bir veya iki üst ve alt seviyelerine enstrümantasyon uygulanabilir. Günümüzde erişkinlerde sıklıkla uygulanan minimal invaziv cerrahi tekniğinin, daha kısa cerrahi süre ve daha az kan kaybı gibi avantajlara sahip olmakla birlikte, çocuklarda uygulanabilirliğini gösteren çalışma mevcut değildir. Çocuk hastalarda hangi yöntemin seçileceği konusunda yeterli çalışma bulunmamaktadır.

\section{Fleksiyon-distraksiyon yaralanması}

Fleksiyon-distraksiyon yaralanması (emniyet kemeri yaralanması, Chance kırığı), travmanın rotasyon eksenine bağlı olarak, arka kolonun distraksiyon veya kompresif fleksiyon kuvvetleri altında yaralanması sonucu oluşur. ${ }^{[27]}$ Çocuk hastalarda buna, yaklaşık \%40 oranında iç organ ve kafa yaralanmaları eşlik edebilir. ${ }^{[10]}$ Bu nedenle, yüksek enerjili abdominal travma geçiren hastalar mutlaka omurga yaralanmaları açısından da araştırılmalıdır.

Saf kemik, saf bağ/disk ya da kombine kemik/bağ/ disk yaralanması şeklinde gerçekleşebilir. Ligamentöz ve disk yaralanmasının varlığı MR ile değerlendirilmelidir (Şekil 3e). Eğer saf kemik yaralanması şeklinde ise, ekstansiyon alçısı veya TLSO sonrasında çekilen röntgende redüksiyon iyi ise sekiz hafta konservatif tedavi uygulanır. Uygun redüksiyon sağlanamamışsa posterior enstrümantasyon ve stabilizasyon ile cerrahi tedavi düşünülmelidir. Büyük çocuklardan saf bağ/ disk yaralanması olan hastalarda, konservatif tedavi ile iyileşme potansiyeli daha azdır ve çoğu zaman cerrahi tedavi gerekir. Küçük çocuklarda ise cerrahi tedavi öncesi alçılama denenebilir. Cerrahi müdahalede yaralanma seviyesinin bir veya iki üst ve alt omurgasının enstrümantasyonu, anatomik redüksiyon için yaralanma seviyesine posteriordan kompresyon uygulanması ve posterolateral füzyon genellikle yeterlidir (Şekil 3).

\section{Kırıklı çıkıklar}

Yüksek enerjili torsiyonel, distraksiyon ve makaslama kuvvetlerinin oluşturduğu majör künt travma ile, dorsolomber bölgede kompleks kırıklar oluşabilir. Bu nadir yaralanma çoğu zaman, kök, medulla spinalis veya kauda ekina yaralanması ile sonuçlanır. Bu tür yaralanmanın cerrahi redüksiyonu ve enstrümantasyon ile stabilizasyonu, dekompresyon için önden ve/veya arkadan girişim yapılması gereklidir.

\section{Apofiziyel kırık ve fitıklaşma}

Apofiziyel kırık ve buna bağlı fitıklaşma, genellikle fiz hattının halen açık olduğu 10-14 yaşları arasında oluşur. ${ }^{[28]}$ Genellikle, çocukluk çağında ağırlık kaldırma veya zorlayıı bir aktiviteyi takiben başlayan radiküler ağrı ile kendini gösterir. Diğer muhtemel semptomlar; 

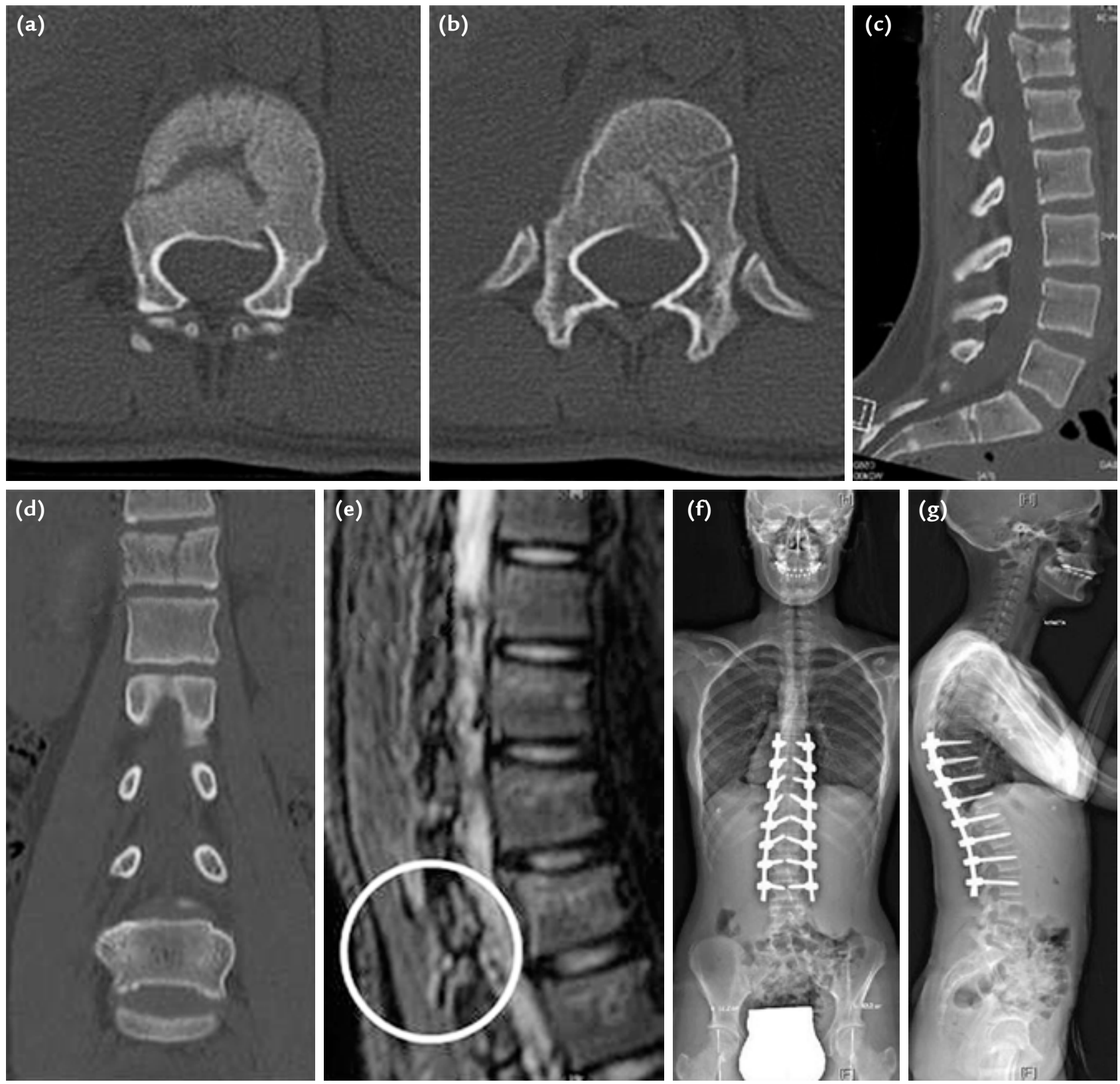

Şekil 3. a-g. On iki yaşında kız çocuğunda araç içi trafik sonrası oluşan fleksiyon-distraksiyon komponentli T12 patlama, T11, L1 ve L2 çökme kırıkları. BT'de kanal işgali ve yükseklik kaybı izlenmektedir (a-d). Sagittal MR kesitinde arka bağ kompleksindeki lezyon görülmektedir (e, daire ile işaretli). Olgunun posterior enstrümantasyon ve füzyon ile tedavisi ve ameliyat sonrası AP ve lateral grafileri $(f, g)$.

alt bel ağrısı, bacaklarda azalmış duyu ve motor kuvvetsizlik, semer tarzı perianal duyu kaybı, idrar ve gaita inkontinansı gibi, kauda ekina basısı bulguları olabilir. Fıtıklaşan apofiz medüller kanal ya da foramene deplase olabileceğinden, erişkinlerde görülen disk fitıklaşmalarına benzer. Uzun kemik epifizyolizinde olduğu gibi, genellikle fizin hipertrofik bölgesinden kırık şeklinde gerçekleşir ve alt endplate üste göre daha fazla etkilenir. Erişkindeki disk fitıklaşmasına benzer şekilde, foramen veya spinal kanal daralmasına bağlı kök basısı ve/veya kauda ekina oluşur ve bunlara ait bulgular ile seyreder.

Kırılan ya da fitıklaşan apofiz spontan redükte olabilir. Dolayısıyla, röntgende bu yaralanma fark 
edilmeyebilir. Klinik şüphe durumunda çekilen MR ile fiz hattında ödem görülmesiyle tanı konulur. Ayrıca, fıtıklaşmanın yeri ve sinir yapıya bası miktarı da tespit edilebilir.

Nörolojik bulguların mevcut olduğu omurilik basısı durumunda cerrahi dekompresyon ve limbusun rezeksiyonu, nörolojik bulgusu yok ise sekiz hafta anti-inflamatuvar ilaç ve TLSO korse ile tedavi edilir. Hastaların az bir kısmında kronik bel-sırt ağrısı olabilmektedir.

\section{Spinöz ve transvers çıkıntı kırıkları}

Dorsolomber bölgede spinöz transvers çıkıntı kırıkları, genellikle künt travma sonucu oluşur ve nadiren iç organ yaralanması ile birlikte görülür. Alt lomber bölgede spinöz çıkıntı kırıkları, instabil pelvis kırıklarında iliolumbar bağların avulsiyonu sonucu oluşabilir. Genellikle semptomatik tedavi ve ağrı tedavisi yeterlidir.

\section{Radyolojik Bulgu Olmaksızın Spinal Kord Yaralanması (Spinal Cord Injury Without Radiologic Abnormality SCIWORA)}

ilk defa 1982 yılında Pang ve Wilberger tarafından tanımlanmış olup, röntgende veya BT'de herhangi kırık veya çıkık gözlenmeksizin spinal kord yaralanması mevcuttur. Omurga anatomi farklılıklarından ötürü, SCIWORA erişkinlere göre çocuklarda çok daha fazla görülmekte olup, genellikle üst servikal bölge etkilenir. MR, spinal kordda ödem, hemoraji ve iskemiyi gösterebilir. SCIWORA tedavisi konservatif olup, 12 hafta immobilizasyon uygulanır; sonrasında dinamik radyografi ile instabilite varlığı araştırılır.

\section{Spinal Kord Yaralanması ve Kauda Ekina Sendromu}

Spinal kord yaralanması ve kauda ekina sendromu, yüksek enerjili travma ile ilişkilidir. Bu hastalarda ATLS protokolü uygulanmalı ve hastalar, eşlik edebilecek başka yaralanmalar ve yaralanma sonrası ortaya çıkabilecek komplikasyonlar açısından yakından izlenmelidir.

Spinal kord yaralanması kısmi veya tam olabilir ve derecesi ASIA (American Spinal Injury Association) ölçeğine göre sınıflandırılır (Tablo 1). ASıA skalasının öncüsü olan Frankel ve ark.'nın tanımlamış olduğu spinal kord yaralanması evrelemesi de kullanılabilir (Tablo 2). Kısmi spinal kord yaralanması veya kauda ekina sendromu olan hastada görüntüleme yöntemleri ile bası yapan lezyon tespit edilirse, acil dekompresif cerrahi uygulanmalıdır. ${ }^{[29]}$ Biyomekanik instabilite tespit edilen olgularda; hastanın travma sonrası bakımını kolaylaştırmak, instabiliteye bağlı gelişebilecek ikincil nörolojik yaralanmaları önlemek, mobilizasyon ve fizyoterapiye başlama süresini kısaltmak ve uzun dönemde deformite oluşumunu önlemek için dekompresyona ek olarak enstrümantasyon ile stabilizasyon uygulanır.

Nörolojik yaralanma geçiren çocuk ve adolesan hastalar ilerleyici omurga deformitesi oluşumu riskine karşı iskelet gelişiminin sonuna kadar takip edilmelidir. ${ }^{[30]}$ Takiplerde $10^{\circ}$ 'nin altında skolyoz tespit edilen olgularda, deformitenin ilerlemesini önlemek ve cerrahiden kaçınmak için korse kullanılabilir. ${ }^{[31]}$ Eğrilikleri $10^{\circ}$ ile $20^{\circ}$ arası olan spinal kord yaralanmalı hastalarda korse kullanımı, cerrahinin ileri tarihe ertelenmesini sağlarken, $20^{\circ}$ üstü eğriliklerde skolyozun ilerlemesini önlemekte başarısız olmaktadır. ${ }^{[3,31]}$

Spinal kord yaralanmasına bağlı oluşan skolyozda; deformitenin cerrahi olarak düzeltilmesi, stabilizasyon ve füzyon endikasyonları ilerleyici deformite varlığı ve

Tablo 1. ASIA ölçeği

\begin{tabular}{ll}
\hline ASIA A: (Tam lezyon) & $\begin{array}{l}\text { Tam motor ve duysal fonksiyon kaybı } \\
\text { (S4 ve S5 segmentleri dahil) }\end{array}$ \\
ASIA B: (Kısmi lezyon) & $\begin{array}{l}\text { Tam motor kayıp; fakat nörolojik } \\
\text { düzey altında sensöriyel fonksiyon } \\
\text { korunmuş. }\end{array}$ \\
ASIA C: (Kısmi lezyon) & $\begin{array}{l}\text { Motor ve duysal fonksiyon kaybı var. } \\
\text { Ancak lezyon seviyesi altında önemli } \\
\text { kas gruplarında Evre 3'ten az kas } \\
\text { kurveti korunmuş. }\end{array}$ \\
ASIA D: (Kısmi lezyon) & $\begin{array}{l}\text { Motor ve duysal fonksiyon kaybı } \\
\text { var. Ancak lezyon seviyesi altında } \\
\text { önemli kas gruplarında Evre 3 veya } \\
\text { daha yüksek düzeylerde kas kurveti } \\
\text { korunmuş. }\end{array}$ \\
ASIA E: (Normal) & Motor ve duysal fonksiyonlar normal.
\end{tabular}

Tablo 2. Frankel spinal kord yaralanması evrelemesi
A Lezyon altında tam motor ve duysal paralizi.
B Tam motor paralizi, ama bir miktar duysal fonksiyon korunmuş.
C Rezidü motor fonksiyon mevcut ama pratik kullanım yok.
D Kullanılabilir motor fonksiyon ama yine de normal seviyenin altında.
E Normal. 
oturma denge bozukluğu olmasıdır. Ancak, bu hasta grubunda cerrahi tedavinin ciltte yara oluşumu, idrar ve gaita inkontinansı nedeniyle yara yeri enfeksiyonu, dekubit ülseri gelişimi gibi önemli komplikasyonları mevcuttur. Ayrıca spinal kord yaralanması olan çocuklarda sonradan siringomiyeli oluşabileceğinden, bu hastalar progresif nörolojik defisit açısından da yakından takip edilmelidir. Bu hastalar MR ile değerlendirilmeli ve bası yapan bir sirinks varlığında cerrahi dekompresyon uygulanmalıdır.

\section{SONUÇ}

Çocuk omurgası erişkin omurgasının minyatür bir modeli değildir. Travma sonucu oluşacak omurga yaralanmasının tipi, gelişmekte olan omurganın anatomisinin erişkin omurgasına göre değişiklikler göstermesi gibi farklılıklar vardır. Bunun yanında, gelişen ve büyümeye devam eden çocuk omurgası, spinal kord yaralanmasından sonra nörolojik tablonun düzelmesi ve omurga yaralanmasında remodelizasyon potansiyeli taşır. Yaralanmanın nadir olmasına bağlı cerrahi deneyim eksikliği, literatürde çocuk omurga yaralanması ile ilgili yeterli sayıda çalışmanın bulunmaması, tedavi teknikleri üzerine tam bir konsensus bulunmaması, tanı ve tedavide zorlukları da beraberinde getirmektedir. İyileşme potansiyeli erişkinlere göre daha yüksek olmasına rağmen, çocuk omurgasında mevcut yaralanmanın tanısı sıklıkla gecikmektedir. Erken tanı ve tedavinin uygulanması, uzun dönemde meydana gelebilecek deformite, ek nörolojik sorunlar gibi komplikasyonların önlenmesi açısından büyük önem taşır.

\section{KAYNAKLAR}

1. Akbarnia BA. Pediatric spine fractures. Orthop Clin North Am 1999;30(3):521-36. Crossref

2. Dogan S, Safavi-Abbasi S, Theodore N, Chang SW, Horn EM, Mariwalla NR, Rekate HL, Sonntag VKH. Thoracolumbar and sacral spinal injuries in children and adolescents: a review of 89 cases. J Neurosurg 2007;106(6 Suppl):426-33. Crossref

3. Parent S, Dimar J, Dekutoski M, Roy-Beaudry M. Unique features of pediatric spinal cord injury. Spine 2010;35(21 Suppl):S202-8. Crossref

4. Cirak B, Ziegfeld S, Knight VM, Chang D, Avellino AM, Paidas CN. Spinal injuries in children. J Pediatr Surg 2004;39(4):60712. Crossref

5. Carreon LY, Glassman SD, Campbell MJ. Pediatric spine fractures: a review of 137 hospital admissions. J Spinal Disord Tech 2004;17(6):477-82. Crossref

6. Junkins EP Jr, Stotts A, Santiago R, Guenther E. The clinical presentation of pediatric thoracolumbar fractures: a prospective study. J Trauma 2008;65(5):1066-71. Crossref

7. King J, Diefendorf D, Apthorp J, Negrete VF, Carlson M. Analysis of 429 fractures in 189 battered children. J Pediatr Orthop 1988;8(5):585-9.
8. Hadley MN, Zabramski JM, Browner CM, Rekate H, Sonntag VK. Pediatric spinal trauma. Review of 122 cases of spinal cord and vertebral column injuries. J Neurosurg 1988;68(1):1824. Crossref

9. Herzenberg JE, Hensinger RN, Dedrick DK, Phillips WA. Emergency transport and positioning of young children who have an injury of the cervical spine. The standard backboard may be hazardous. J Bone Joint Surg Am 1989;71(1):15-22. Crossref

10. Santiago R, Guenther E, Carroll K, Junkins EP Jr. The clinical presentation of pediatric thoracolumbar fractures. J Trauma 2006;60(1):187-92. Crossref

11. Louman-Gardiner K, Mulpuri K, Perdios A, Tredwell S, Cripton PA. Pediatric lumbar Chance fractures in British Columbia: chart review and analysis of the use of shoulder restraints in MVAs. Accid Anal Prev 2008;40(4):1424-9. Crossref

12. Brown JK, Jing $\mathrm{Y}$, Wang $\mathrm{S}$, Ehrlich PF. Patterns of severe injury in pediatric car crash victims: Crash Injury Research Engineering Network database. J Pediatr Surg 2006;41(2):362-7. Crossref

13. Sledge JB, Allred D, Hyman J. Use of magnetic resonance imaging in evaluating injuries to the pediatric thoracolumbar spine. J Pediatr Orthop 2001;21(3):288-93. Crossref

14. Mahan ST, Mooney DP, Karlin LI, Hresko MT. Multiple level injuries in pediatric spinal trauma. J Trauma 2009;67(3):53742. Crossref

15. Dare AO, Dias MS, Li V. Magnetic resonance imaging correlation in pediatric spinal cord injury without radiographic abnormality. J Neurosurg 2002;97(1 Suppl):33-9. Crossref

16. Anderson PA, Montesano PX. Morphology and treatment of occipital condyle fractures. Spine 1988;13(7):731-6. Crossref

17. Papadopoulos SM, Dickman CA, Sonntag VK, Rekate HL, Spetzler RF. Traumatic atlantooccipital dislocation with survival. Neurosurgery 1991;28(4):574-9. Crossref

18. Landells CD, Van Peteghem PK. Fractures of the atlas: classification, treatment and morbidity. Spine 1988;13(5):450-2. Crossref

19. Pilge $H$, Prodinger PM, Bürklein D, Holzapfel BM, Lauen J. Nontraumatic subluxation of the atlanto-axial joint as rare form of acquired torticollis: diagnosis and clinical features of the Grisel's syndrome. Spine 2011;36(11):E747-51. Crossref

20. Fielding JW, Hawkins RJ, Hensinger RN, Francis WR. Atlantoaxial rotary deformities. Orthop Clin North Am 1978;9(4):955-67.

21. Goldstein HE, Anderson RCE. Classification and Management of Pediatric Craniocervical Injuries. Neurosurg Clin North Am 2017;28(1):73-90. Crossref

22. Vaccaro AR, Lehman RA Jr, Hurlbert RJ, Anderson PA, Harris M, Hedlund R, Harrop J, Dvorak M, Wood K, Fehlings MG, Fisher C, Zeiller SC, Anderson DG, Bono CM, Stock GH, Brown AK, Kuklo T, Öner FC. A new classification of thoracolumbar injuries: the importance of injury morphology, the integrity of the posterior ligamentous complex, and neurologic status. Spine 2005;30(20):232533. Crossref

23. Sellin JN, Steele WJ, 3rd, Simpson L, Huff WX, Lane BC, Chern JJ, Fulkerson DH, Sayama CM, Jea A. Multicenter retrospective evaluation of the validity of the Thoracolumbar Injury Classification and Severity Score system in children. J Neurosurg Pediatr 2016;18(2):164-70. Crossref 
24. Savage JW, Moore TA, Arnold PM, Thakur N, Hsu WK, Patel AA, McCarthy K, Schroeder GD, Vaccaro AR, Dimar JR, Anderson PA. The Reliability and Validity of the Thoracolumbar Injury Classification System in Pediatric Spine Trauma. Spine 2015;40(18):E1014-8. Crossref

25. Karlsson MK, Moller A, Hasserius R, Besjakov J, Karlsson C, Ohlin A. A modeling capacity of vertebral fractures exists during growth: an up-to-47-year follow-up. Spine 2003;28(18):2087-92. Crossref

26. Vander Have KL, Caird MS, Gross S, Farley FA, Graziano GA, Stauff M, Segal LS. Burst fractures of the thoracic and lumbar spine in children and adolescents. J Pediatr Orthop 2009;29(7):713-9. Crossref

27. Rennie $W$, Mitchell $N$. Flexion distraction fractures of the thoracolumbar spine. J Bone Joint Surg Am 1973;55(2):38690. Crossref
28. Shirado O, Yamazaki Y, Takeda N, Minami A. Lumbar disc herniation associated with separation of the ring apophysis: is removal of the detached apophyses mandatory to achieve satisfactory results? Clin Orthop Relat Res 2005;(431):1208. Crossref

29. Slotkin JR, Lu Y, Wood KB. Thoracolumbar spinal trauma in children. Neurosurg Clin North Am 2007;18(4):621-30. Crossref

30. Mayfield JK, Erkkila JC, Winter RB. Spine deformity subsequent to acquired childhood spinal cord injury. J Bone Joint Surg Am 1981;63(9):1401-11. Crossref

31. Mehta S, Betz RR, Mulcahey MJ, McDonald C, Vogel LC, Anderson C. Effect of bracing on paralytic scoliosis secondary to spinal cord injury. J Spinal Cord Med 2004;27 Suppl 1:S88-92. Crossref 